Tomasz Kalicki, Joanna Krupa, Sławomir Chwałek Kielce

\title{
GEOARCHAEOLOGICAL STUDIES IN PAPHOS - FIRST RESULTS
}

Abstract: The geoarchaeological research conducted consisted of a geomorphological prospecting of the Paphos region and a geophysical examination of the ancient town of Nea Paphos and its agora. In addition, the morphogenetic processes that shaped the coastal plains of the Cypriot area were also determined and a research hypothesis that could explain the shrinking of the bay and the decline of the harbour north of the cape of Paphos was formulated. The Mala GPR (Ground Penetrating Radar) ProEx System, which is compatible with shielded antenna of 500MHz, was used for the geophysical survey of the area. 95 profiles were completed in a northsouth direction (1m apart) and 51 in an eastwest direction (2m apart). One of the main difficulties was to distinguish the stone structures, as the bottoms of their walls were formed at the natural level of the rock and there were pebble layers located above them. Using versatile geophysical techniques, we have attempted to answer a couple of questions: Was the agora area a fully built-up one and what does the continuation of the walls into undiscovered sections of the agora signify?

Keywords: Geoarchaeology; geomorphology; geophysical survey; georadar; Paphos; Cyprus

\section{Introduction: location and present geographical environment}

Cyprus is the third largest island $\left(9251 \mathrm{~km}^{2}\right)$ of the Mediterranean Sea, located in the eastern part of the basin, about $65-70 \mathrm{~km}$ south of Asia Minor (Czeppe et al. 1966; Dominik et al. 1977; Mydel and Groch 2000; 
Makowski 2006; Puskarz 2008). The island's latitudinal extent is $225 \mathrm{~km}$ and its longitudinal $97 \mathrm{~km}$. Cyprus is a mountainous area, with a denivelation reaching as high as $2000 \mathrm{~m}$. The coastline (about $700 \mathrm{~km}$ long) is diverse and abounds in bays and capes.

Cyprus is located in an obduction zone, which is the term used for the rarely encountered situation in which an oceanic plate runs onto a continental one. In the case of Cyprus, this occurs where the Eurasian plate meets the African. This leads to major neotectonic engagement within the area, resulting in earthquakes (panseismic zone). From a geological point of view, the island is a prolongation of the Taurus Mountains' (a mountain ridge bordering the Anatolian Upland from the south) alpine structures. Cyprus was separated from the Asian mainland towards the end of the Pleistocene and initially consisted of two islands. These were formed by two mountain ranges that were uplifted in the Miocene: the Karpason (Karpasia, Pentadaktilos Mts.) Mountains in the north and the Troodos Mountains in the south. The ranges were separated by a tectonic depression known as the Mesaoria. In the Quaternary, this depression was filled with alluvia. Today, it is a flat lowland (denivelations up to $100 \mathrm{~m}$ ), about $130 \mathrm{~km}$ long and $24-48 \mathrm{~km}$ wide. Two thirds of the island is covered by mountains. The Karpason Mountains (the highest point of which is Kiparisovounos $1019 \mathrm{~m}$ a.s.1.) mainly consist of Jurassic, Cretaceous and Tertiary limestone and flysch, whereas Troodos (where Cyprus' highest point is located Olympus $1951 \mathrm{~m}$ a.s.1.) has a geological structure typical of alpine systems. Its centre consists of a crystalline core, built of plutonic and volcanic rock (gabbro, diabase, serpentinite) covered and surrounded by Mesozoic sedimentary rock, from which a high plain located in the southeastern part of the island has been formed. This high plain becomes a coastal plain as it reaches the sea.

Cyprus' climate is semi-tropical Mediterranean. The summer (VI-IX) is hot and dry and the winter (XI-III) can be described as benign. The average annual temperature is about $19^{\circ} \mathrm{C}\left(12^{\circ} \mathrm{C}\right.$ in mountainous areas). The average temperature in January is $10-12^{\circ} \mathrm{C}$ (ground frosts occur in the mountains) and in August $26-28^{\circ} \mathrm{C}\left(\max\right.$. temp. above $\left.45^{\circ} \mathrm{C}\right)$. About $90 \%$ of precipitation occurs during the winter. Between VI and IX, rainfall is very scarce and the average annual precipitation is about $500 \mathrm{~mm}$. The lowest readings (about 350-400 $\mathrm{mm}$ ) were recorded in the central part of Mesaoria, which is cut off by mountains. The highest readings (up to $1000 \mathrm{~mm}$ ) were taken in the Troodos Mountains, where snowfall also occurs. 
All of the island's rivers are periodic (Pl. 1: 1), flowing for only a few weeks a year. The most substantial are Kouris, Geryllis and Diarizos, while the longest are Pediaios and Gialias. There are no natural freshwater lakes, but four bodies of salt water do exist. These conditions result in a severe lack of fresh water. Water distribution is based on artificial retentive reservoirs and the wanton exploitation of groundwater, which subsequently lowers its level. Water management difficulties occurred on the island even in ancient times (Kathijotes and Azina 2014).

Brown soil is encountered in the forested parts of the Troodos Mountains, whilst in the Karpason Mountains rendzic leptosoil dominates. In the eastern part of the island, terra rossa soil is the most prevalent and the Mesaoria is dominated by fertile alluvial soils.

The island belongs to the Mediterranean phyto- and zoogeographic zone, although its flora and fauna have been massively anthropogenically altered. Maquis occurs up to $500 \mathrm{~m}$ a.s.l., although it is replaced by a local variation, 'frigana', on less fertile soil. There is evergreen forest above $500 \mathrm{~m}$ a.s.1., but it only covers $13 \%$ of this area. The dominant species are pine, stone pine and oak. In its highest parts, areas of natural cedar wood have been preserved. Above $1850 \mathrm{~m}$ a.s.1., high-mountain meadows occur. As far as the animal world is concerned, the most abundant fauna is avifauna (40 species of migrating birds). Mammals and reptiles are scarce.

\section{Aims and methods of study}

Geoarchaeological research was carried out between 29th September and 10th October 2014. It consisted of a geomorphological prospecting of the Paphos region and a geophysical examination of the Agora.

The aim of geophysical research was to investigate the economic infrastructure of the ancient agora, whilst the aim of geomorphological prospection was to determine the natural processes that modelled the area in ancient times.

The initial results of the geomorphological study of the morphology and sediments near Paphos and the geophysical research on the Agora are presented in this article.

\section{Geomorphological survey}

The surveyed area was the archaeological site known as the Archaeological Park in Paphos, as well as its surroundings. Several route sections were 
completed and diving in several locations around the peninsula allowed the research team to identify underwater structures located in the coastal area. During field examination, the morphology and alluvia of two valleys were surveyed. One of the valleys surrounds the peninsula from the north (Koskinas), whilst the second does likewise from the south (Ezousas). The variations of structure and landform type were also determined in the Xeros and Diarizos basins on the southern slopes of the Troodos Mountains, which is an alimentary area for rivers flowing towards Paphos.

The Paphos region has a very simple geological structure. It is made up of marine terrace sediments uplifted in the Quaternary (MIS - marine isotope stage; age of terraces according to Zomeni 2012), which are dissected by river valleys with terraces and alluvial insertions (Pls. 1: 2, 2: 1). The crystalline core (an ophiolite sequence) of the Troodos Mountains is located about $20 \mathrm{~km}$ to the northeast. About $5 \mathrm{~km}$ from the coast, the rocks of various formations belonging to the Mesozoic cover disappear under Quaternary sediments to create a massively karstified carbonate rock basement.

Certain edges of lower marine terraces were exploited as quarries in ancient times (P1. 2: 2) and their rough, karst surfaces were artificially levelled (Pl. 3: 1).

The karstified carbonate rock bottom also forms a contemporary abrasive platform on significantly long segments of cliff coast (P1. 3: 2).

The karst depressions, presumably from the Tertiary, are often filled with terra rossa. One of these holes was dug up during 2014 excavation work on the Agora.

The periodic rivers are able to transport coarse material. Ezousa alluvia in the estuary section can be divided into two parts: fine-grained (located in its lower part) and coarse (located in the upper) (P1. 4: 1). This change of sedimentation type may be connected to anthropogenical environment changes, such as deforestation, change of land use etc. However, this hypothesis has yet to be confirmed and still requires future detailed examination. These contemporary alluvia can be seen as a typical result of anthropogeny, as they consist of a mixture of coarse, clastic sediments and anthropogenic rubbish (P1. 4: 2).

Similar alluvia occur in the Koskinas periodic river, the estuary of which is located north of the cape of Paphos (Pl. 5). It transports coarse, clastic material to an underwater abrasive platform that can be seen on images from Google Earth. These sediments are transported south along the shore line. When the shore line reaches the cape, at the site of the ancient town 
of Paphos, the sediment accumulates in the bay to its north (known as Fanari beach nowadays). This process may have led to the disappearance of the bay and transformation of the bay into mainland. In ancient times, the bay may also have been used as a harbour (P1. 6).

The accumulated algae layers on the beach (Pl. 7), which are meshed with clastic beach sediments, allow us to date this process. Beach sediment typically contains organic interbedding, which can be used in radiocarbon dating. An examination of this material can determine the rate and timeframe of the bay's shrinking and this research (e.g. geological drilling in the beach area) should be conducted as the next stage of the survey.

\section{Geophysical research}

\section{GPR research area location}

One of the most popular research methods used in archaeology is the noninvasive identification of a site. This can lead to highly fruitful collaboration between prospecting and excavating archaeologists, if data exchange occurs in both directions (Neubauer 2004, 160).

A ground-penetrating radar survey was carried out on the Agora of the ancient city of Nea Paphos. The area of research covered $c .100 \mathrm{~m}^{2}$. However, due to the fact that pre-existing obstacles were blocking the profiling route (trenches, shrubs, large stone blocks, ditches), this area was reduced to about $80 \mathrm{~m}^{2}$. The survey was conducted along two measuring routes. On the N-S axis, 95 measuring lines were placed, whilst 51 were placed on the W-E axis (Pl. 8).

The purpose of this research was non-invasive reconnaissance in order to determine the location of architectural structures belonging to the ancient agora.

Down to a surveying depth of about $2 \mathrm{~m}$, the ground had been formed contemporarily and contained sand and limestone boulders up to $0.5 \mathrm{~m}$ in diameter (possibly building material). Due to high wave attenuation, both the interpretation of these results and the locating of massive objects remains problematic. A solid, rock roof (highly karstified) appears at approximately 2m (P1. 9: 1).

\section{Method description}

The GPR method is classified as a radiowave method, as it uses electromagnetic radiation. It is based on the variation of a dielectric constant factor in its medium. It is a non-destructive technique used in surveying 
the continuity and homogeneity of ground. The name is abbreviated to GPR (Ground Penetrating Radar) and signal frequencies range from $10 \mathrm{MHz}$ to several GHz.

The surveying appliance consists of a central unit and two antennas one that transmits and one that receives (P1. 9: 2). The transmitting antenna sends an electromagnetic signal, which is reflected, refracted or suppressed. The reflected wave is registered by the receiving antenna. The distance from an object is calculated on the basis of the time elapsed between the sending of the signal and the receiving of its echo.

A $400 \mathrm{MHz}$ antenna is able to receive usable information from up to $8 \mathrm{~m}$ below ground level, depending on the geological structure of the ground and the measuring conditions. A $1 \mathrm{GHz}$ antenna allows a survey of up to one meter below ground level to be conducted and provides a $1 \mathrm{~cm}$ resolution. The conditions required to be able to collect data involve an existing contrast of dielectrical constant values between the medium and the surveyed object (Karczewski 2007).

A $250 \mathrm{MHz}$ antenna has also been used on similar sites, for example in the Classical Greek cities of Elis and Mantinea in the Peloponnese (Moffat et al. 2015) and when seeking structures (Neubauer et al. 2014).

The survey was conducted by moving both antennas along the profile. The results of the examination come in the form of an echogram (wave image), which displays the internal structure of the ground (P1. 9: 2).

\section{Work range and methodology}

During the survey, a GPR device manufactured by the MALA ProEx company was used. The device was equipped with a $500 \mathrm{MHz}$ shielded antenna. The transmitter and the receiver were connected by fibre-optic cables and controlled via a laptop computer (Pl. 9: 2). The software used during the survey was GroundVision 2.0.

In order to achieve a detailed image of the subsurface layer, the following parameters were applied: 1 . sampling frequency of the signal received $14,050 \mathrm{MHz}$; 2. samples -506 ; 3. per time $-35.9 \mathrm{n}$; 4. distance between tracks $-1 \mathrm{~m}(\mathrm{~N}-\mathrm{S})$ and $2 \mathrm{~m}(\mathrm{E}-\mathrm{W})$.

The GPR profile lines were driven parallel, $1 \mathrm{~m}$ apart from each other in the N-S direction and $2 \mathrm{~m}$ apart in the W-S.

The GPR data was processed using Reflex software. The data processing sequence was as follows:

Move start time

This is the first procedure, during which a static correction in time direction is achieved. It allows a proper timescale representation. 
The beginning of the signal is set by moving the scale to the reading of the first arrival (start time value).

\section{Substract DC-shift}

This option allows a 'zero mean' to be established through the subtraction of an existing time constant shift. As a filter parameter, two time values (1.time and 2.time) must be entered. Within this time range, the mean is calculated for each trace, which is subsequently subtracted from all samples of each trace. It must therefore be guaranteed that the mean value in the corresponding time range matches the shift you wish to eliminate.

This procedure was used before the gain function.

Background removal

This function helps to calculate the average trace of the whole echogram in terms of both time and distance. The average value is subtracted from each registered track. The goal of this procedure is to remove the noise of the electronic signals.

Bandpass frequency

This procedure involves the application of a bandpass filter to the readings. It is generally carried out manually when monitoring the frequency spectrum. The process allows frequencies containing random noise to be removed. The signal spectrum is multiplied by the filter value.

Gain function

The application of this feature represents a very important stage of signal processing. The signal amplitude lowers as recording time increases. However, due to the numerous external phenomena that alter the signal, the amplitude is enhanced.

Average xy-filter

This filter calculates the average of a selectable xy-area for each time step. The average is taken using both a number of different traces (parameter no. of traces $[\mathrm{x}]$ ) and a number of different samples (parameter no. of samples [y]). This filter method suppresses trace and time dependent noise and acts as a lowpass filter for both $\mathrm{x}$ - and $\mathrm{y}$-(time).

Div. Compensation

This filter acts on each trace independently and compensates for geometricial divergence losses.

\section{GPR results survey}

The profiles were taken using a site grid as a basis. The largest number of anomalies occurred in the northern part of the Agora. Clearly visible anomalies can be noted at the site where the crepidoma is located (Pl. 10). 
The main factor taken into consideration during analysis was whether anomaly depth exceeded the accumulation layer. The depth axis was set for dry lithosol and the echograms' maximum reach was $2-2.5 \mathrm{~m}$. The first $0.4 \mathrm{~m}$ of the accumulation layer consisted of homogeneous ground, whilst the following layer was of a medium density in which thick rubble predominantly appeared). Only the most permanent structures, such as stone construction remains, could be seen distinctly and have their depth calculated.

\section{Summary}

The GPR survey was carried out in the Agora area of the ancient site of Nea Paphos and resulted in the identification of various independent structures lying underground. In the E-W profiles, several anomalies distinct from the rest of the signals can be observed. One of these is an anomaly situated between the first and second to fourth metre, which occurs on practically all of the profiles presented (P1. 11: 1). Another anomaly is located between the 10th and 18th metre. As with the previous example, it continues (with very infrequent interruptions) throughout the first $60 \mathrm{~m}$. A distinct signal is also present at the end of the profile trace. Between the 80th and 86th metre, an anomaly reaching beyond a depth of $1.5 \mathrm{~m}$ can be distinguished.

The entire Agora area abounds with anomalies derived from structures lying underground. These are probably the basements and lower parts of the walls of the buildings that presumably once existed here. The profile located $31 \mathrm{~m}$ from the 200/100 line is worthy of special consideration due to a distinct signal that is visible here. The signal is present in the first three metres and reaches below a depth of two metres (P1. 11:2).

The N-S profiles indicate similar anomalies in terms of parameter. In the first two metres, an anomaly reaching up to two meters in depth is visible. This continues with infrequent interruptions across the wholeAgora. Another anomaly is also visible on the opposite side of the area surveyed. As with the previous example, it runs continuously (albeit with rare interruptions) across the whole Agora. In the middle part of the site, many anomalies can be seen that are undoubtedly indicative of the underground structures present in this area. They can be seen as a continuation of structures uncovered in three ongoing excavations in Trenches I, II and III.

Finally, it should be noted that the kind of device used for this research (the GPR Mala ProEx with a $500 \mathrm{MHz}$ shielded antenna) is appropriate 
for such tasks and can be used successfully on similar sites and in similar climactic conditions.

\section{Conclusion}

The geomorphological prospecting of the Paphos peninsula and its surrounding area has allowed us to determine the set of morphogenetic processes that modelled the coastal plains in this part of Cyprus. A research hypothesis explaining the shrinking of the bay and the decline of the harbour north of the cape of Paphos has also been formulated.

Future research will be focused on two main areas:

1. Drilling in the beach area in order to reveal the stratigraphy of its sediments. These results can serve as the basis for a time model of coastline changes north of Paphos.

2. Geomorphological mapping and dating of the Koskinas river alluvia in order to determine the periods of most intensive material transport into the delta, which led to the transformation of the bay north of Paphos into mainland.

The geophysical survey on the Agora in Paphos has allowed us to come to the following conclusions:

1. Many anomalies are visible underground.

2. The shielded antenna of $500 \mathrm{MHz}$ is suitable for this kind of survey.

3. Made ground areas within the Agora are difficult to interpret.

\section{References}

Czeppe Z., Flis J. and Mochnacki R. 1966. Geografia fizyczna świata. Warsaw.

Dominik A., Królikowski K. and Szaflarski J. 1977. Stownik geografii świata, vol. 1. Warsaw.

Karczewski J. 2007. Zarys metody radarowej. Krakow.

Kathijotes N. and Azina P. 2014. Development of water management technologies in ancient Cyprus. In Programme and Abstracts from the Third Geoarchaeological Conference in Warsaw Impact of the Holocene Rapid Climate Events (8.2, 5.9, $4.2 \mathrm{ka}$ and Others) on Past Cultures and Civilizations, 28th-29th November 2014, 9-10. Warsaw. 
Makowski J. 2006. Geografia fizyczna świata. Warsaw.

Moffat I., Papadopoulos N., Donati J., Sarris A., Kalayci T., CuencaGarcía C., Cantoro G.,Argyriou N.,Armstrong K., Kalogiropoulou E., Manataki M., Simon F. X., Karapanagiotou A. V. and HadjiSpiliopoulou G. 2015. Multi-component geophysical survey at the Classical Greek cities of Mantinea and Elis. Antiquity Journal (Projects Gallery) 89/345.

Mydel R. and Groch J. (eds.) 2000. Przeglądowy Atlas Świata. Part 2: Azja. Krakow.

Neubauer W. 2004. GIS in archaeology - the interface between prospection and excavation. Archaeological Prospection 11/3, 159-166.

Neubauer W., Gugl C., Scholz M., Verhoeven G., Trinks I., Löcker K., Doneus M., Saey T. and Meirvenne M. 2014. The discovery of the school of gladiators at Carnuntum, Austria. Antiquity 88/339, 173-190.

Puskarz J. (ed.) 2008. Geografia świata. Encyklopedia PWN. Środowisko przyrodnicze. Warsaw.

Zomeni Z. 2012. Quaternary Marine Terraces on Cyprus: Constraints on Uplift and Pedogenesis and the Geoarchaeology of Palaipafos. (Unpublished doctoral thesis, Oregon State University). Corvallis, Oregon.

Tomasz Kalicki

Institute of Geography Jan Kochanowski University tomaszkalicki@ymail.com

Joanna Krupa

Institute of Geography Jan Kochanowski University joannakrupa@poczta.fm

Sławomir Chwałek Institute of Geography Jan Kochanowski University slawomirchwalek@gmail.com 


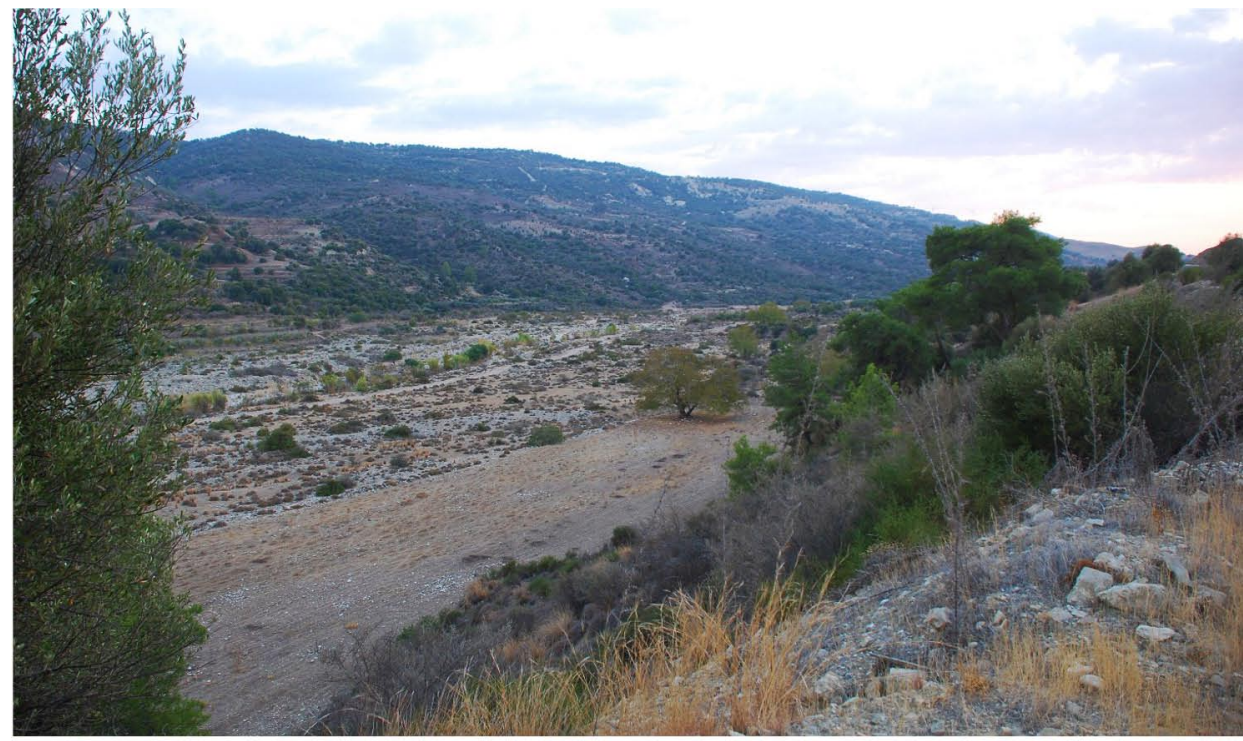

1

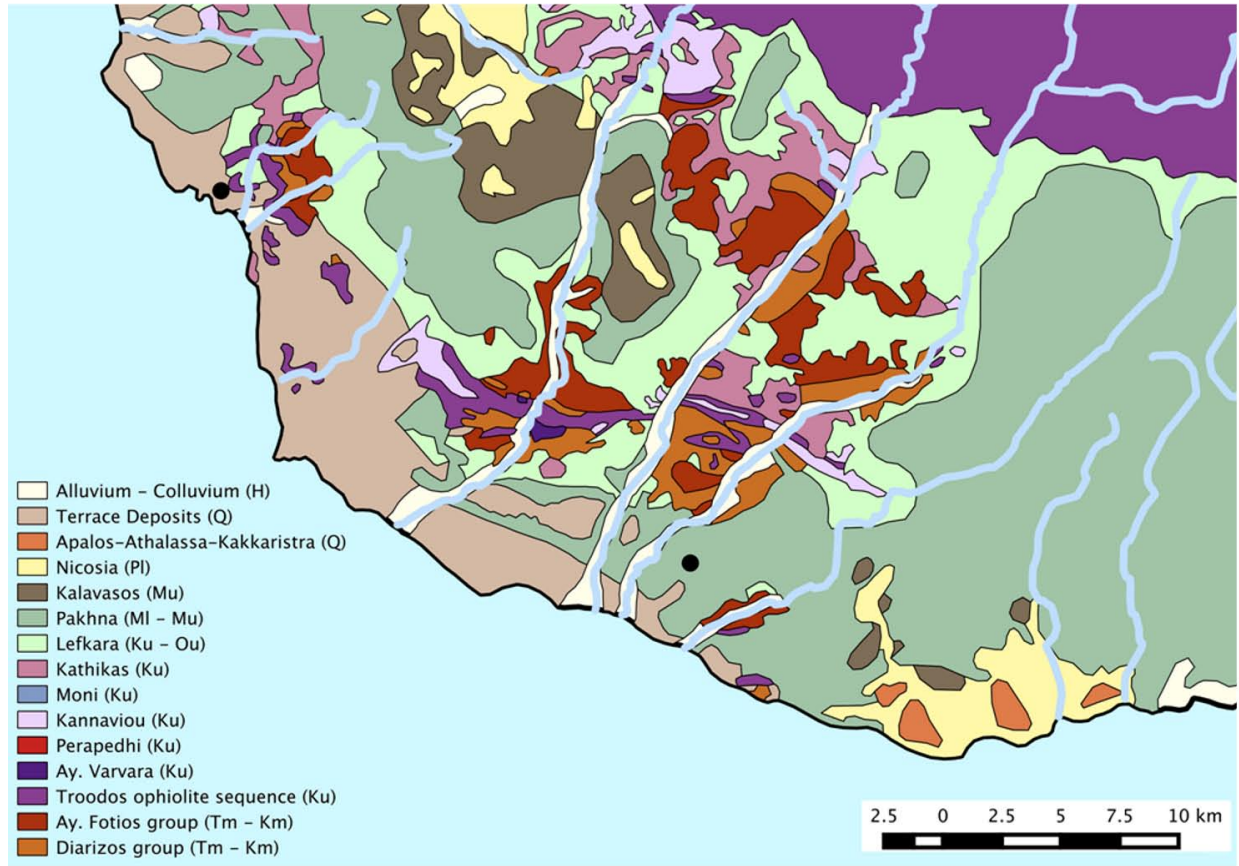

P1. 1. 1 - Braided alluvial plain of a periodic river in the Troodos Mts. Photo by T. Kalicki; 2 - Geological map of SW Cyprus. Reproduced. Courtesy Geological Survey Department in Cyprus 

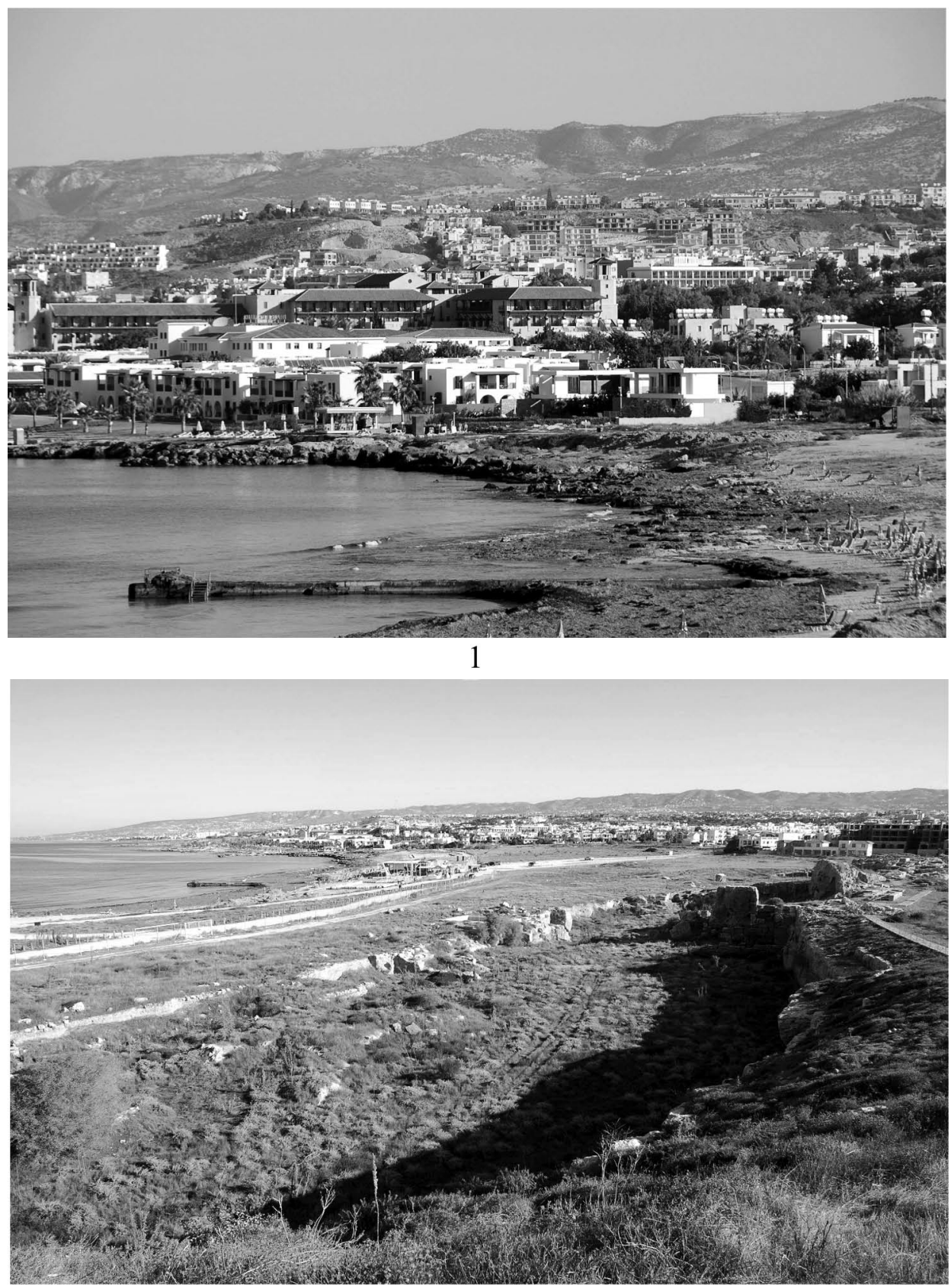

Pl. 2. 1 - Uplifted Quaternary marine terraces (MIS 5-7 and MIS 9) in Paphos. Photo T. Kalicki; 2 - Edge of marine terrace anthropogenically transformed by an ancient quarry. Photo by T. Kalicki 


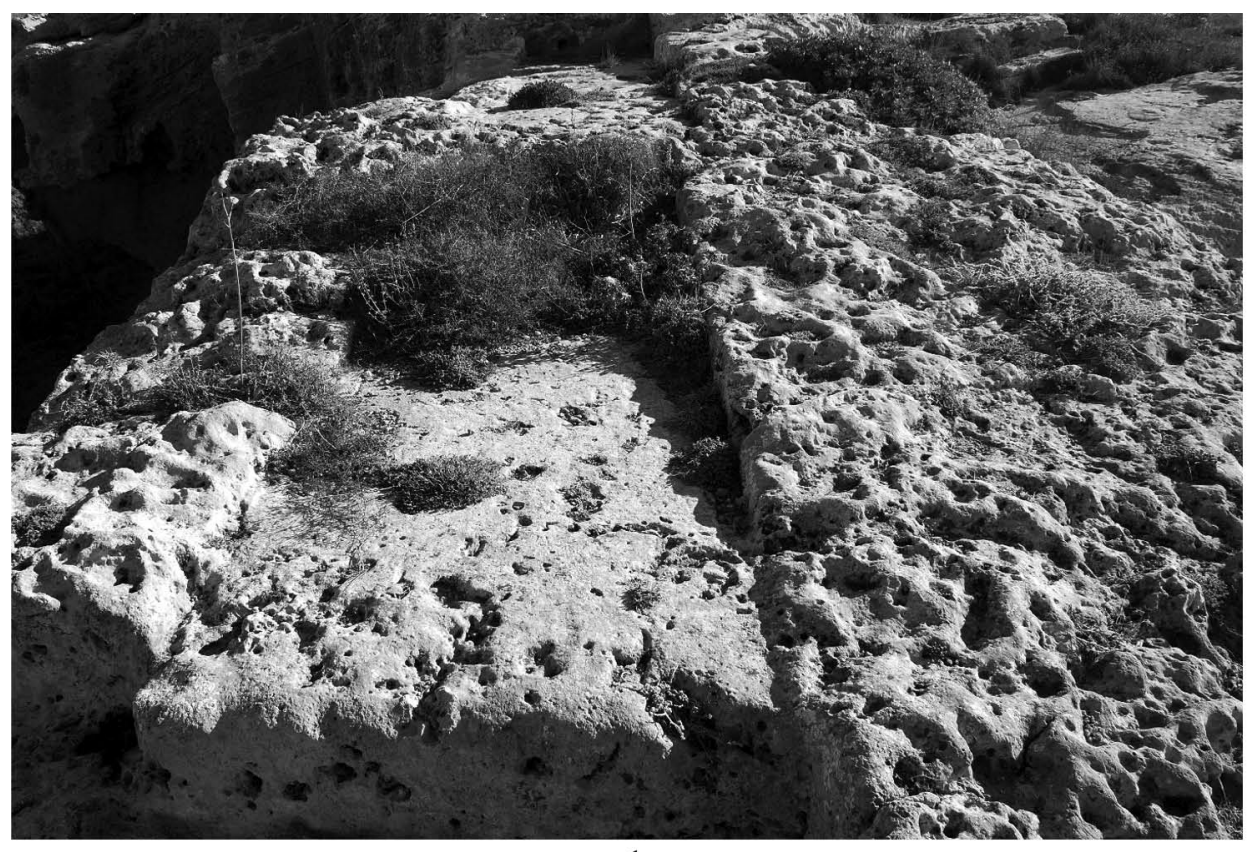

\section{1}

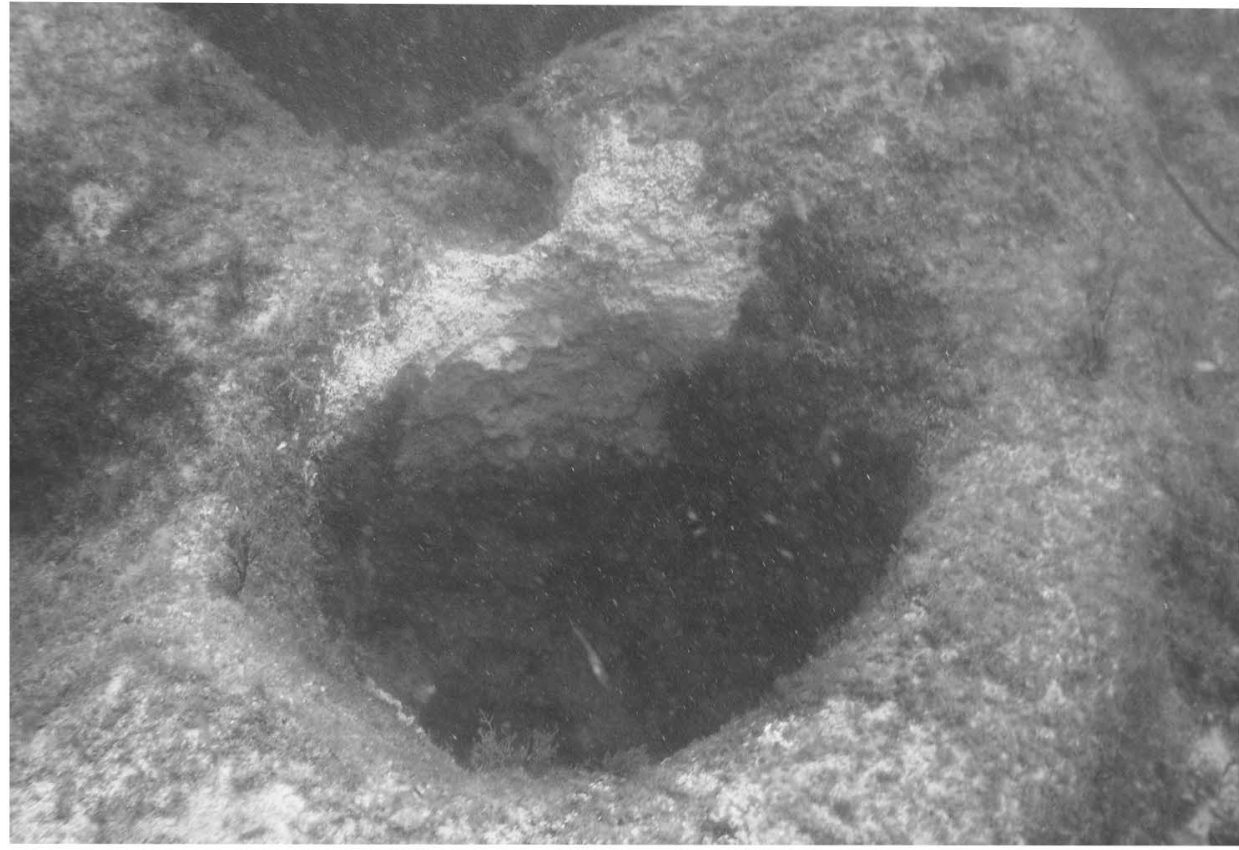

Pl. 3. 1 - Karstic surface of naturally and anthropogenically levelled limestone. Photo by T. Kalicki; 2 - Karstic depresions in limestone on an underwater abrasion platform. Photo by S. Chwałek 

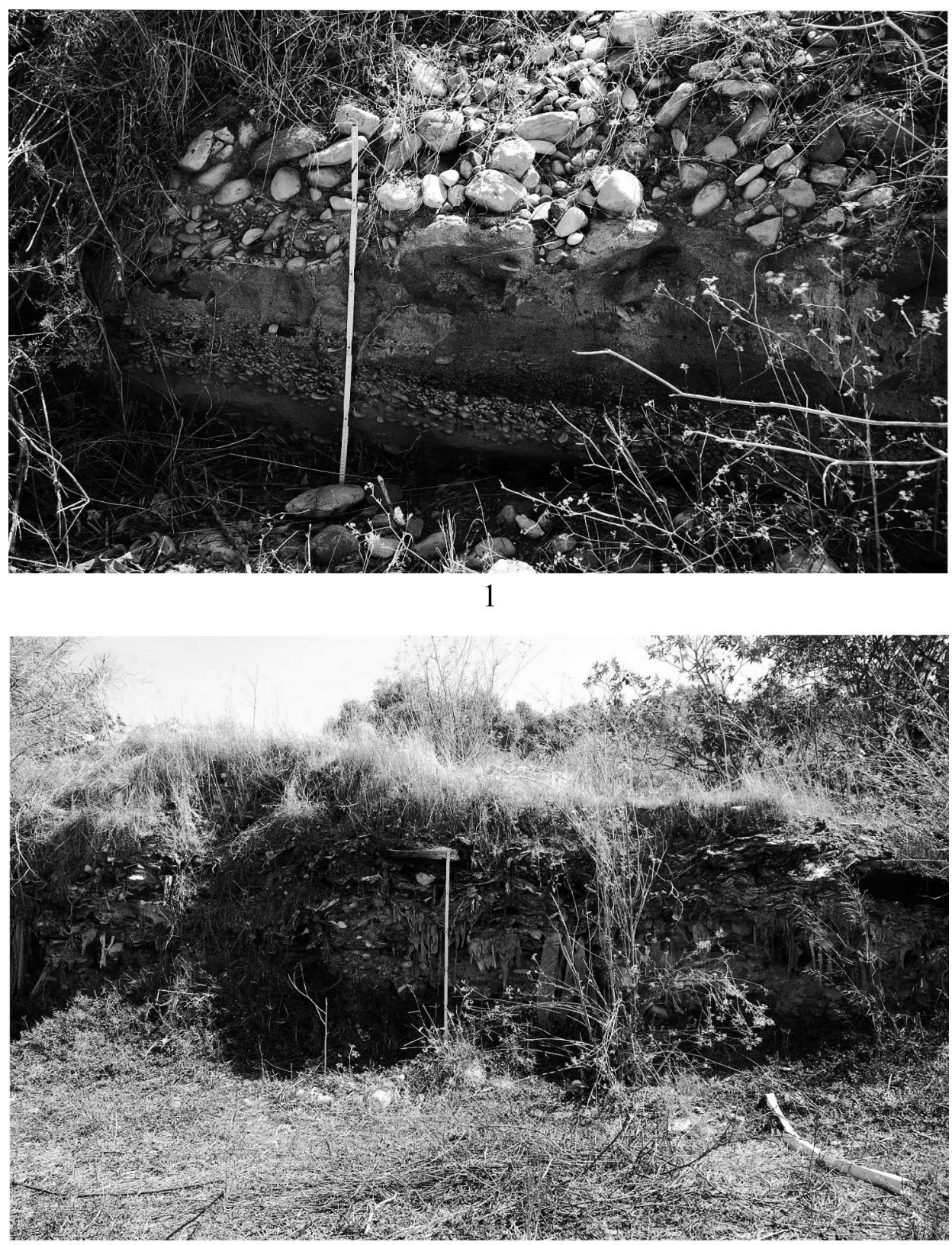

2

P1. 4. 1 - Bipartite alluvia in the lowest section of the Ezousa river valley. Photo by T. Kalicki; 2 - Present-day alluvia of the Ezousa river - gravel and boulders mixed with anthropogenic rubbish. Photo by T. Kalicki 


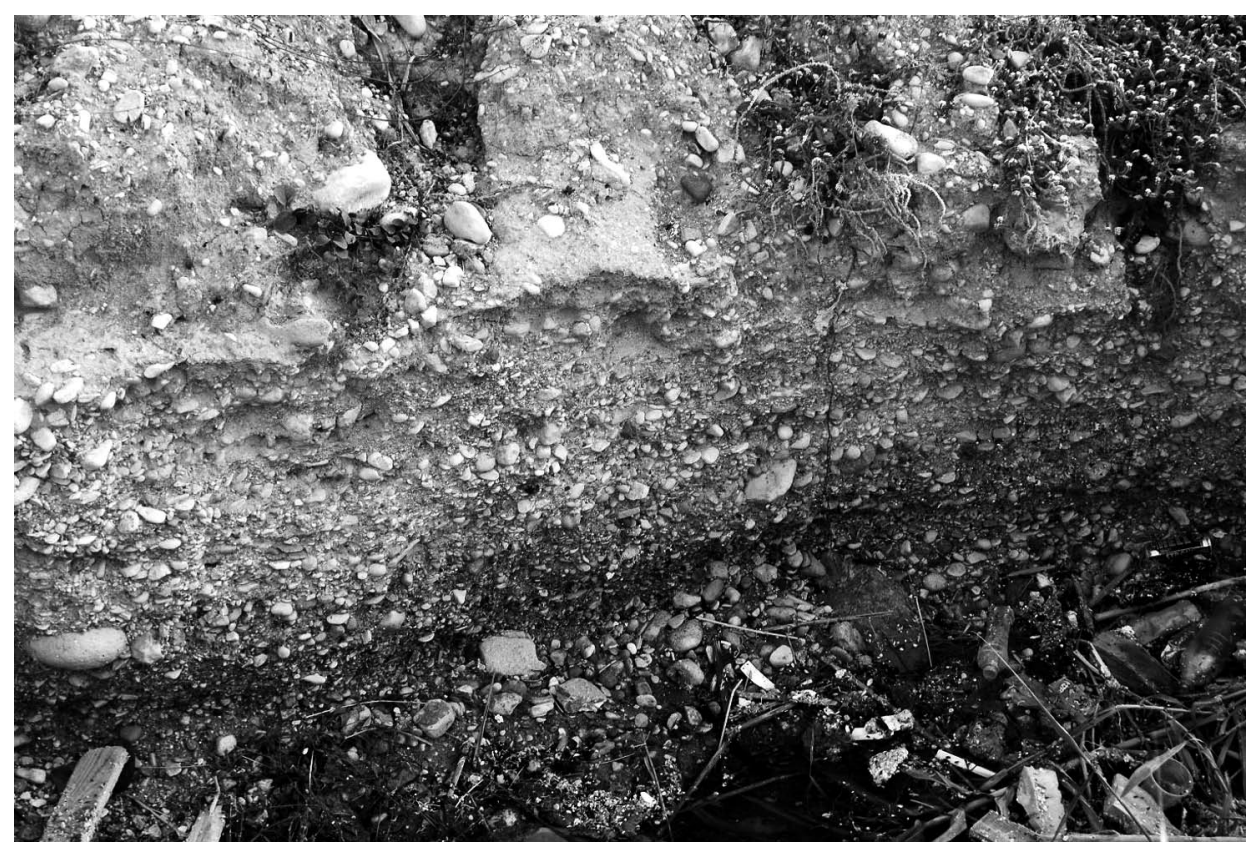

P1. 5. Coarse alluvia of the Koskinas river in its lowest section. Photo by T. Kalicki 


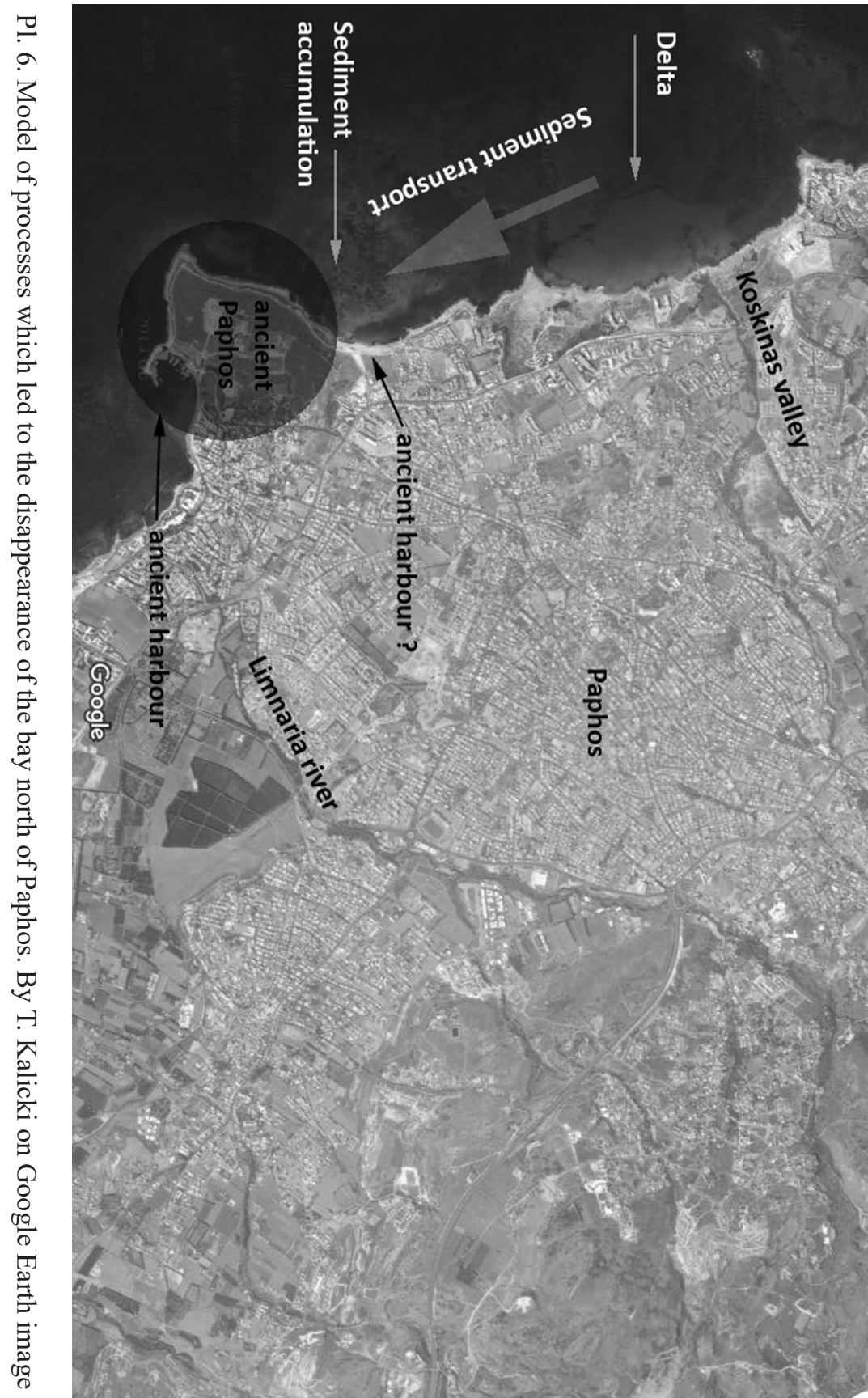




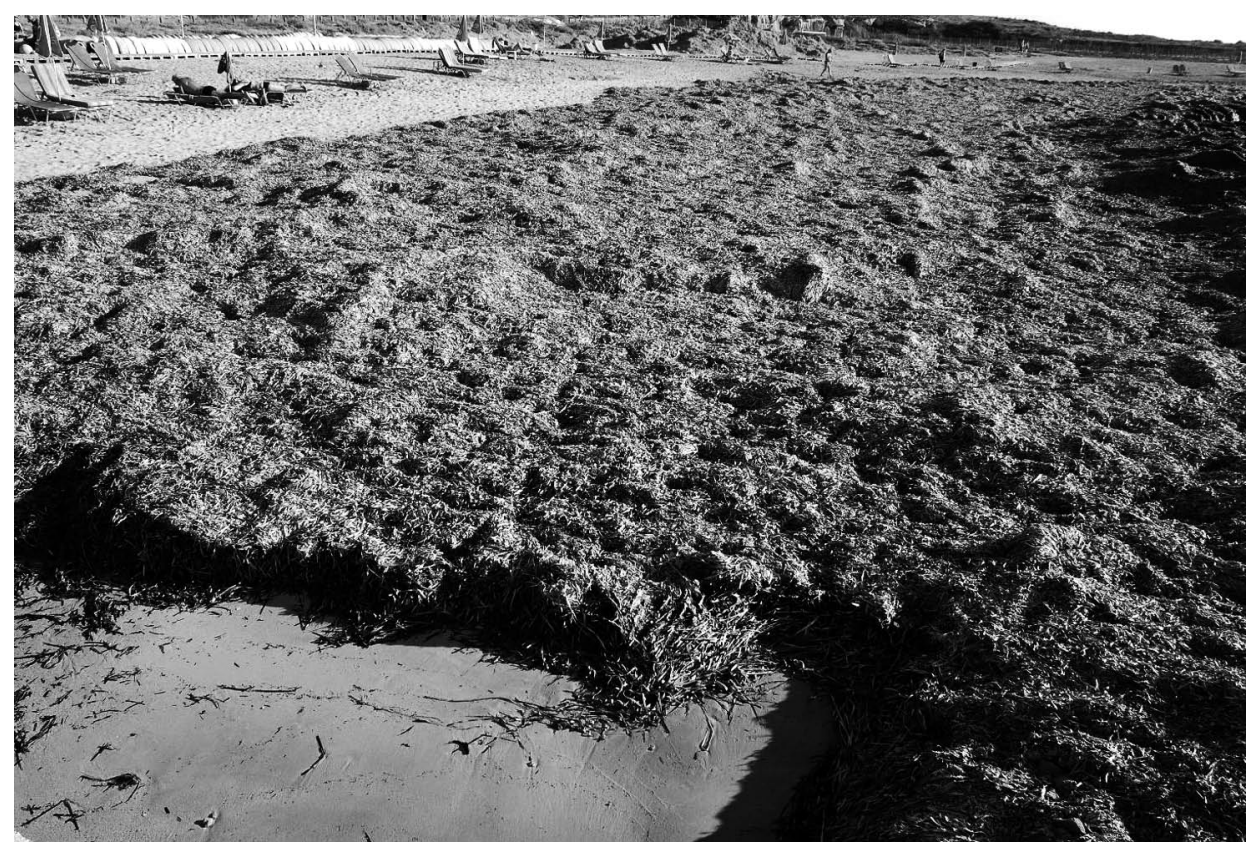

Pl. 7. Accumulated algae layer on the sandy beach. Photo by T. Kalicki 

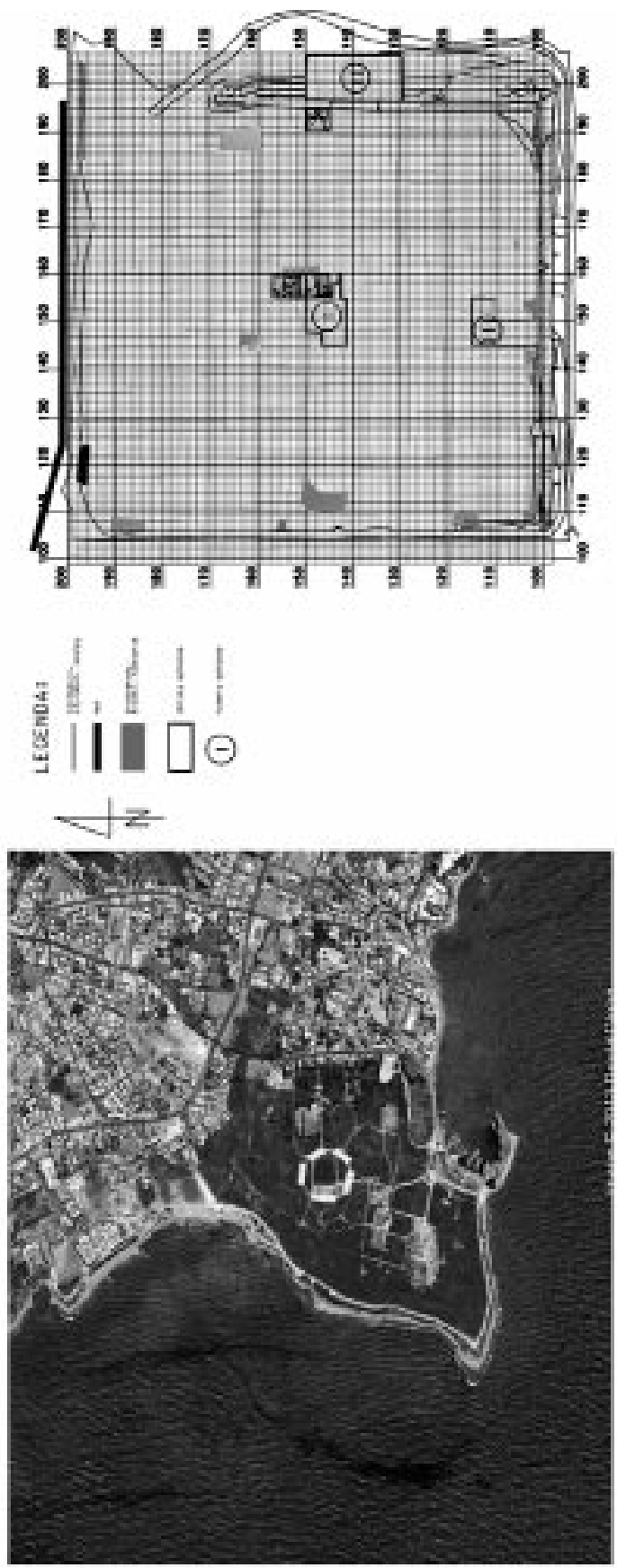

Pl. 8. GPR research area location. By S. Chwałek and Ł. Bąk on Google Earth image 

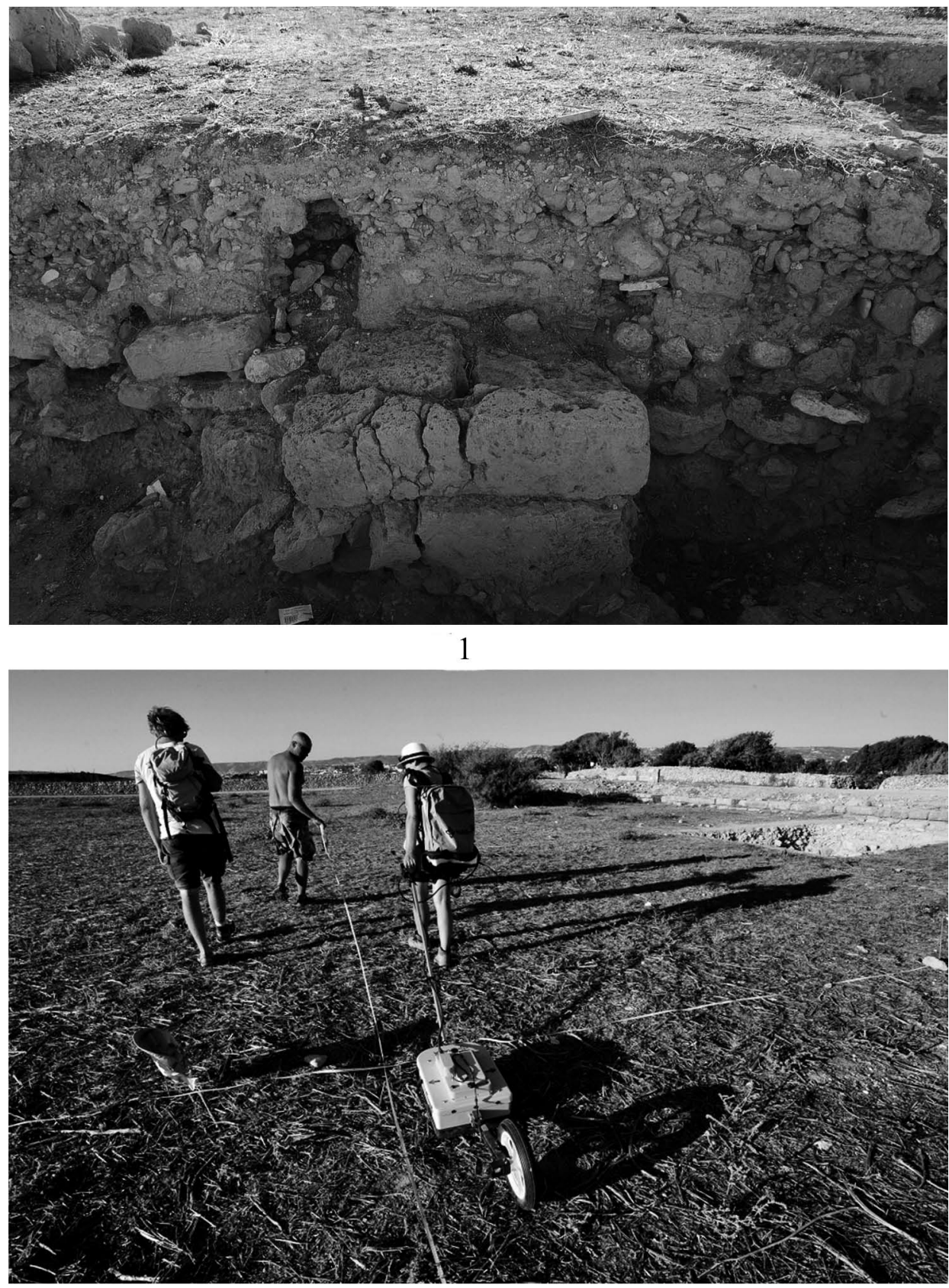

2

Pl. 9. 1 - Made ground on the site. Photo by T. Kalicki; 2 - GPR surveying of the site and the surveying appliance. Photo by R. Słaboński 


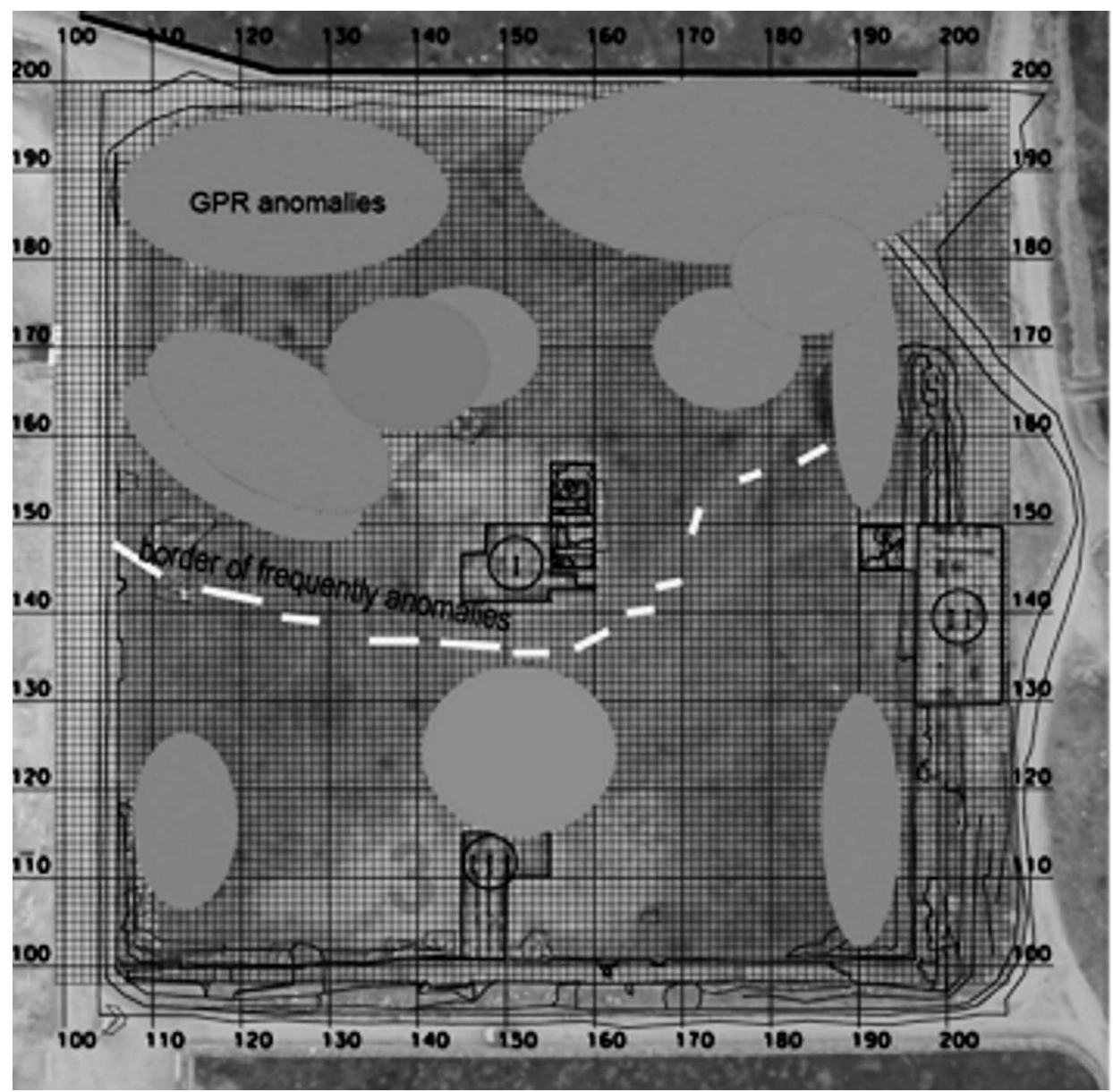

P1. 10. Map of the Agora with anomalies. By S. Chwałek and J. Krupa 

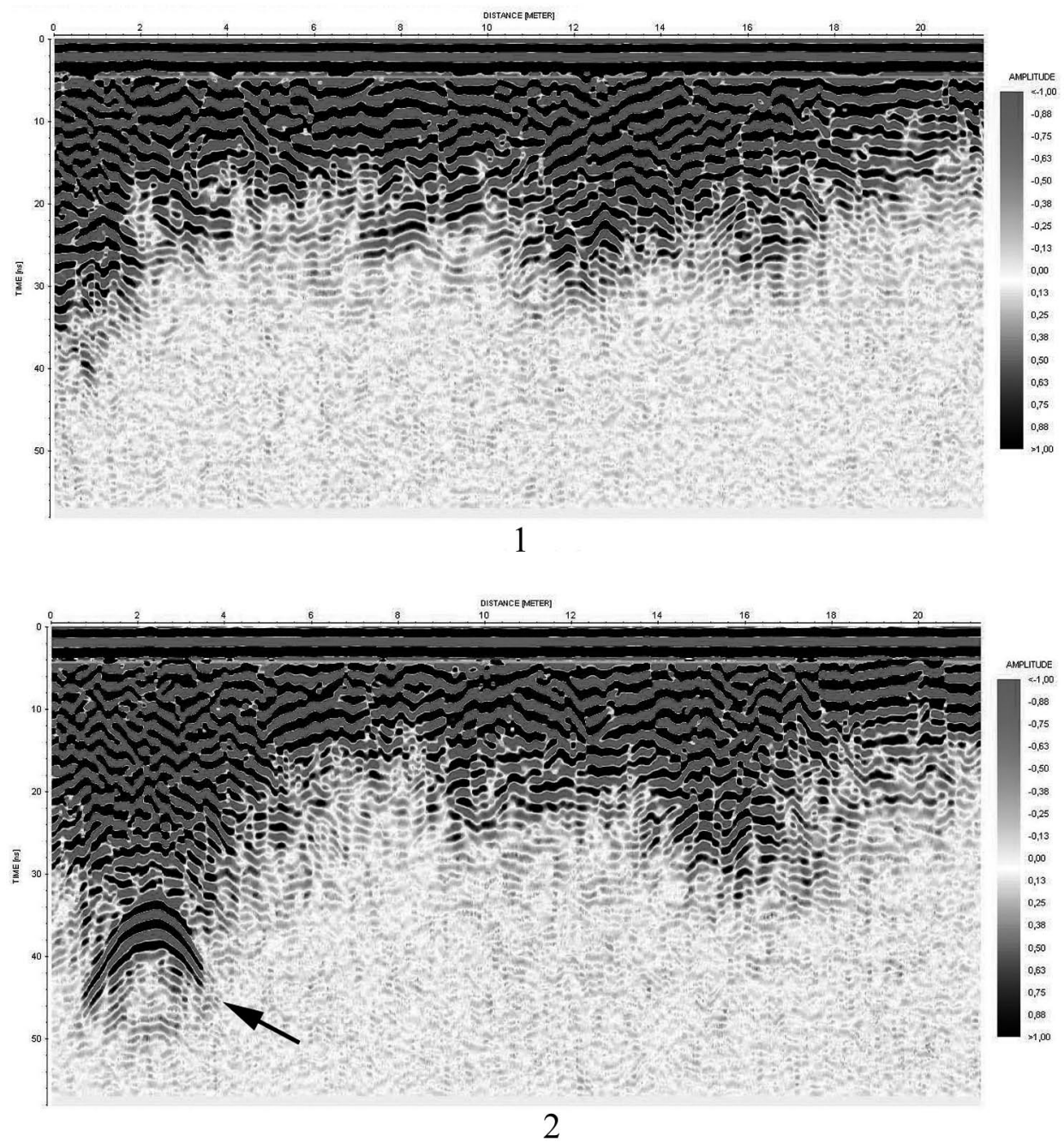

P1. 11.1 - Radar profile of anomalies, E-W direction. By S. Chwałek and J. Krupa 2 - Radar profile with very clear anomalies, E-W direction. By S. Chwałek and J. Krupa 